\title{
Relationship between Seminal Tumor Necrosis Factor- $\alpha$ and sperm quality in Iraq
}

\author{
${ }^{1}$ Ali Saliem Abdulridha,${ }^{2}$ Frial Jameel Abid \\ ${ }^{1}$ Assist. Prof. in College of pharmacy/Kufa University \\ ${ }^{2}$ Assist. Prof. in College of Science / Babylon University
}

\begin{abstract}
Tumor necrosis factor- $\alpha(T N F-\alpha)$ it is a cytokine secreted by macrophage and plays a critical role in sperm quality due to it can induced sperm membrane lipid peroxidation by increasing ROS releasing within spermatozoa. Our results were proved that the sperm vitality becomes exceedingly worse due to elevation of TNF- $\alpha$ level in semen.
\end{abstract}

\section{Introduction}

Tumor necrosis factor- $\alpha$ mainly secreted by macrophages in response to inflammation, infection, and cancer, also it aid in programmed cell death (apoptosis). Many studies have shown that TNF- $\alpha$ is existing in semen of both normal males and among patients with identified bacterial infections, both are have same concentration of TNF- $\alpha$ (Hussenet et al., 1993). Other studies have instead shown that TNF- $\alpha$ level in semen of patients with bacterial infection are more elevated than in healthy control (Gruschwiz et al., 1996), also it has been shown that leukocytospermia and/or bacteriospermia are associated with higher release of TNF- $\alpha$ (Kocak et al., 2002; Perdichzzi et al., 2007; Nabil and Moamen, 2009).

Unlike broad spectrum of cytokines, they required coordination between NFAT and AP-1 in order to stimulate their releasing, with exception of TNF $\alpha$ promoter acivity, which independent on this cooperative recruitment of AP-1(Macian et al., 2000). Instead of, the releasing of TNF $\alpha$ depend on NFATC2 rather than NFAT/AP-1 pathway, (Bhushan et al., 2008; Cirl et al., 2008). In addition, other investigations were reported that $\mathrm{TNF} \alpha$ can induced sperm membrane lipid peroxidation by increasing ROS releasing within spermatozoa (Buch et al., 1994; Martinez et al., 2007).

\section{Materials and Methods}

A total one hundred semen samples were collected from patients who attended to Fertility Center in AL Sadder teaching hospital in Al najaf city-Iraq at a period from June 2013 to Jan 2014, the ages of patients and control ranged from (18-55) years. The control samples involved 20 healthy fertile men.

Samples collection: the seminal fluid samples will collected from patients after informed them how to obtain the sample by sterile method into sterile container to avoid external contaminants. Then, the samples were cultured onto suitable media before preceding the next step to prevent contaminations which may be occurring in next steps. After completion liquefactions period, the samples were examined for fertility parameters and other microscopically findings.

Thereafter, the specimens were centrifuged at $3000 \mathrm{rpm}$ for 15 minutes to obtain seminal plasma, then the concentration of TNF- $\alpha$ were estimated by using ELISA kit as recommended by manufacturer company.

The patients specimens were divided into three groups according to type of bacterial infection, all these group compared with control group as shown in table-1

Table (1) Patients groups of study

\begin{tabular}{|c|c|c|}
\hline Groups & Describe & Number \\
\hline Group 1(G1) & Gram negative infected patients & 16 \\
\hline Group2(G2) & Gram positive infected patients & 41 \\
\hline Group3(G3) & Uninfected subfertile patients & 43 \\
\hline Group4(G4) & All patients & 100 \\
\hline Control & Healthy fertile persons & 20 \\
\hline
\end{tabular}




\section{Results and Discussion}

In present study the measurement levels of TNF- $\alpha$ were yielded that there is a significant elevation $(\mathrm{P}<0.05)$ only in G1 mean \pm SE $580 \pm 155.3$, while both G2 $305.5 \pm 53.7$ and G3 $317.4 \pm 63.7$ have no significant differenced $(\mathrm{P}>0.05)$ Figure-1.

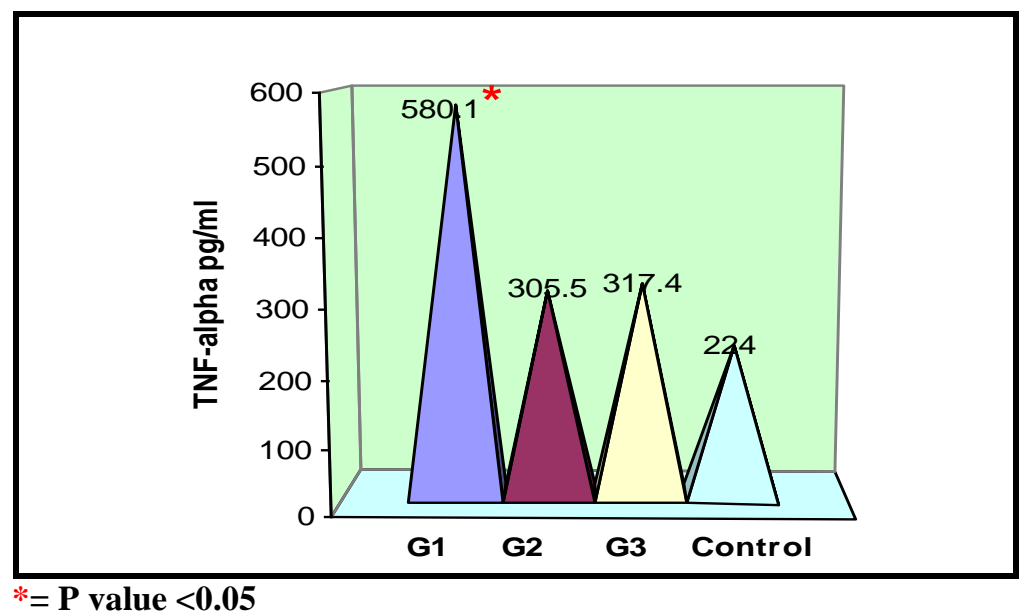

Figure -1 Concentration of TNF- $\alpha$ among patients and control group

Many studies have shown that TNF- $\alpha$ is existing in semen of both normal males and among patients with identified bacterial infections, both are have same concentration of TNF- $\alpha$ (Hussenet et al., 1993). Other studies have instead shown that TNF- $\alpha$ levels in semen of patients with bacterial infection are more elevated than in healthy control (Gruschwiz et al., 1996), also it has been shown that leukocytospermia and/or bacteriospermia are associated with higher release of TNF $\alpha$ (Kocak et al., 2002; Perdichzzi et al., 2007; Nabil and Moamen, 2009).

In contrast, our results that concerned to TNF $\alpha$ level were disagreement with those studies, due to the present finding was yielded that the concentration of TNF- $\alpha$ was significantly rising only in patients infected with G-ve bacteria rather than G+ve bacteria.

This circumstance can be interpret by various approaches, with regard to a broad spectrum of cytokines, they required a coordination between NFAT and AP-1 in order to stimulate their releasing with exception of TNF $\alpha$ promoter activity, which independent on this cooperative recruitment of AP-1(Macian et al., 2000).

Instead, the releasing of TNF- $\alpha$ depend on NFATC2 rather than NFAT/AP-1 pathway, and because of the UPEC can actively alters immune response by suppression of NFKB signaling pathway, while a putative corepression of AP-1 signaling via LPS containing bacteria mainly UPEC which has HiyA that stimulates cytokine expression depending on NFATC2 instead of NFAT signaling pathway(Bhushan et al., 2008; Cirl et al., 2008).

Therefore, this interpretation could be explains the presence of significant mounting in concentration of $\mathrm{TNF} \alpha$ only in G1 group, that illustrated in current study. Notably, it has been reported that TNF $\alpha$ can induced sperm membrane lipid peroxidation by increasing ROS releasing within spermatozoa (Buch et al., 1994; Martinez et al., 2007), this may support that the TNFa plays a key role in regulation of apoptosis process throughout binding with type-1 TNF $\alpha$ receptor (TNFR1) within sperm membrane, this linking cause trimerazation of certain adaptor proteins, which aid to recruits and activates of caspase- 8 , which considered as a trigger of apoptotic cascade initiation. This process probably mediated by existence of ROS, lastly, sperm death can be occurred due to these activities (Aitken et al., 1992; Barroso et al., 2000).

Furthermore, the results of current study were provided that all studied groups (G1, G2, G3, and G4) were have significant decreased $(\mathrm{P}<0.05)$ in main important semen parameters including sperm count, activity, and morphology(personal unpublished study), while the correlations between concentration of TNF- $\alpha$ and all these parameters were have variable relations but no significant $(\mathrm{P}>0.05)$ table-2. 
Table-2 Relationship between TNF- $\alpha$ with semen parameters among patients groups and control.

\begin{tabular}{|c|c|c|c|c|c|}
\hline \multirow{2}{*}{ Groups } & \multirow{2}{*}{ No. } & \multicolumn{4}{|c|}{ Pperm count } \\
\cline { 3 - 6 } & & $\begin{array}{c}\text { Sperm } \\
\text { active } \\
\%\end{array}$ & $\begin{array}{c}\text { Sperm } \\
\text { morphology } \\
\text { normal\% }\end{array}$ & $\begin{array}{c}\text { Dead Sperm } \\
\%\end{array}$ \\
\hline G1 & 16 & 0.411 & 0.266 & -0.015 & -0.236 \\
\hline G2 & 41 & -0.225 & -0.129 & -0.165 & 0.197 \\
\hline G3 & 43 & -0.009 & 0.033 & -0.079 & 0.028 \\
\hline Total G4 & 100 & -0.016 & 0.016 & -0.109 & 0.044 \\
\hline
\end{tabular}

Data represented as Pearson Correlation Coefficient (r), * significantly correlated with $\mathrm{Zn}$ at the 0.05

level ( $\mathrm{P}$ value $\leq 0.05)$, either positive correlation, or negative correlation which marked as (-).

Several pathophysiological approaches were emerged from experimental and clinical investigations. It was begun to declare influences of certain bacterial infections that concomitant with inflammatory events on spermatozoa. However, beside a powerful mechanism of bacteria that can drive to spermatozoal damage, distortion and eventually male sterility, also it has variety of indirect ways to cause all those harmful changes in sperm.

Elevation of TNF- $\alpha$ which may represent of these ways, primarily due to their role in regulation of apoptosis process, through linking with TNFR1 receptor, then activated of certain adaptor proteins which involved in apoptosis cascade such as caspase- 8 and caspase-9, ultimately activate an excution caspase-3, were expressed, followed by sperm death(Barrosa et al., 2000), also further role of TNF- $\alpha$ represent by that TNF- $\alpha$ could be contributes in decreasing the sperm motility and stimulates membrane lipid peroxidation via inducing ROS production (Martinez et al., 2007).

Collectively, all above findings were corresponded and supported our results were shown that the entire fertility parameters (count, activity, and morphology of sperm) were dropped.

Despite the level of TNF- $\alpha$ have not significant differences except in G1, but sperm parameters remain in worse state. As for G1, were observered that the mounting of TNF- $\alpha$ associated with decreasing of semen quality, probably because their harmful effects on sperm, but the in other groups, their also suffered from these effects, that could be resulting from the altering caused by direct exposure to bacteria only, or via leukocytospermia lonely, or may be due to other causes such as hormonal or environmental (Robbins et al., 2005).

However, this also corresponding to other study were referred to that the apoptosis in sperm may induced by ROS, but not exclusively due to ROS itself, as well as the solo bacteria can induced apoptosis even in absence of ROS, that's mean the direct action of microbes or their products could be induced this alterations in spermatozoa (Villegas et al., 2005).

Otherwise, IL-17 is a proinflammatory cytokine which promotes macrophage to produced TNF- $\alpha$ (Dousset et al., 1997), here can observed that concentration of TNF- $\alpha$ associated with level of IL-17 and this agreement with Qian et al., (2012) were found that IL-17 levels is negatively related to sperm motility, this probability because the synergestic relation between IL-17 and TNF- $\alpha$ versus seminal parameters especially sperm motility and forward move role.

\section{Referances}

[1]. Aitken, R.J., and Buckingham D. (1992). Enhanced detection of reactive oxygen species produced by human spermatozoa with 7 dimethyl amino-naphthalin-1, 2-dicarbonic acid hydrazide. Int. J. Androl., 15:211-219.

[2]. Barroso, G., Morshedi M. and Oehninger S. (2000): Analysis of DNA fragmentation, plasma membrane translocation of phosphatidylserineand oxidative stress in human spermatozoa. Hum. Reprod., 15: 1338-1344.

[3]. Bhushan, S., Tchatalbachev S., Klug J., Fijak M., Pineau C., Chakraborty T., and Meinhardt A. (2008). Uropathogenic Escherichia coli block MyD88-dependent and activate MyD88-independet signalling pathways in rat testicular cells. J. Immunol., 180: 55375547 .

[4]. Buch, J.P., Kolon T.F., Maulik N., Kreutzer D.L. and Das D.K. (1994).Cytokines stimulate lipid membrane peroxidation of human sperm. Fertil. Steril., 62: 186

[5]. Cirl, C., Wieser A., Yadav M., Duerr S., Schubert S., Fischer H., Stappert D., Wantia N., Rodriguez N., Wagner H., Svanborg C. and Miethke T. (2008). Subversion of Toll-like receptor signaling by a unique family of bacterial Toll/interleukin-1 receptor domain-containing proteins. Nat. Med..14:399-406.

[6]. Dousset, B., Hussenet F., Daudin M., Bujan L., Foliguet B. and Nabet P. (1997). Seminal cytokine concentrations (IL-1 beta, Il-2, Il-6, sR IL-2, sR IL-6), semen parameters and blood hormonal status in male infertility. Hum. Reprod., 12: 1476-1479.

[7]. Gruschwitz, M.S., Brezinschek R. and Brezinschek H.P. (1996). Cytokine levels in the seminal plasma of infertile males. J. Androl., $17: 158-163$ 
[8]. Hussenet, F., Dousset B., Cordonnier J.L., Jacob C., Foliguet B., Grignon G. and Nabet P. (1993). Tumour necrosis factor alpha and interleukin2 in normal and infected human seminal fluid. Hum. Reprod., 8:409-411.

[9]. Kocak, I., Yenisey C., Dundar M., Okyay P. and Serter M. (2002). Relationship between seminal plasma interleukin-6 and tumor necrosis factor a levels with semen parameters in fertile and infertile men. Urol. Res., 30:263-267.

[10]. Macian, F., Garcia-Rodriguez C. and Rao A. (2000). Gene expression elicited by NFAT in the presence or absence of cooperative recruitment of Fos and Jun.Embo. J. 19: 4783-4795.

[11]. Martinez, P., Proverbio F. and M.I. Camejo M.I, (2007). Sperm lipid peroxidation and pro-inflammatory cytokines. Asian J. Androl., 9: 102-107.

[12]. Nabil, H. and Moamen L.(2008).Increased Tumor Necrosis Factor Alpha and Interleukin-18 Levels in Seminal Plasma of Infertile Males. J. Med. Sci., 3(2): 115-117.

[13]. Perdichizzi, A., Nicoleitti F., Vignera S., Barone N., D’Agata R., Vicare E. and Calogero A.E. (2007). Effects of Tumour Necrosis Factor- $\alpha$ on Human Sperm Motility and Apoptosis. J. Clin. Immuno., 27(2):152-163.

[14]. Qian, L., Shi Q., Gu Y., Song J., Zhou M. and Hua M.(2012).The relationship between IL-17 and male infertility: Semen analysis. Afr.J.Microbiol.Res.Vol. 6(27), pp.5672-5677.

[15]. Robbins, W.A., Elashoff D.A., Xun L., Jia J., Li N., Wu G. and Wei F. (2005). Effect of lifestyle exposures on sperm aneuploidy. Cytogenetic and Genome Research 111 (3-4): 371-7.

[16]. Villegas, J., Schulz M., Soto L. and Sanchez R. ( 2005). Bacteria induce expression of apoptosis in human spermatozoa apoptosis.10:105- 10 . 